\title{
ERRATUM
}

\section{Erratum to: Cover of Volume 33, Issue 6, 2015}

(C) Chinese Society for Oceanology and Limnology, Science Press, and Springer-Verlag Berlin Heidelberg 2016

Erratum to: Chinese Journal of Oceanology and Limnology

Vol. 33 No. 6, 2015

http://dx.doi.org/10.1007/s00343-015-5157-8, http://dx.doi.org/10.1007/s00343-014-4385-7, http://dx.doi.org/10.1007/s00343-015-4363-8, http://dx.doi.org/10.1007/s00343-015-4361-x, http://dx.doi.org/10.1007/s00343-015-4355-8, http://dx.doi.org/10.1007/s00343-015-4373-6, http://dx.doi.org/10.1007/s00343-015-4360-y, http://dx.doi.org/10.1007/s00343-015-4374-5, http://dx.doi.org/10.1007/s00343-015-4375-4, http://dx.doi.org/10.1007/s00343-015-4381-6, http://dx.doi.org/10.1007/s00343-015-4371-8, http://dx.doi.org/10.1007/s00343-015-4368-3, http://dx.doi.org/10.1007/s00343-015-4366-5, http://dx.doi.org/10.1007/s00343-015-4370-9, http://dx.doi.org/10.1007/s00343-015-4364-7

The presentation of the guest editors in this special issue on the journal cover was partially incorrect in the distributed hard copies. The correct version is given below.

Special Issue on Salt Lakes

From the 12th International Conference on Salt Lake Research

Langfang, 13-18 July 2014

Guest editors:

Mianping ZHENG, Aharon OREN, Nickolai SHADRIN 